\title{
Research Paper: Evaluation of Accident and Disaster Preparedness of Hospitals Affiliated to Ahvaz Jundishapur University of Medical Sciences, Ahvaz, Iran
}

\author{
Mohammad Reza Omidi $^{1^{*}}$ (D), Nabi Omidi² (D, Heshmatollah Asgari ${ }^{3}$ (D) \\ 1. Department of Industrial Engineering, Payame Noor University, Tehran, Iran. \\ 2. Department of Management, Payame Noor University, Tehran, Iran. \\ 3. Department of Economics, Faculty of Literature and Humanities, Ilam University, Ilam, Iran.
}

\begin{tabular}{|c|c|}
\hline $\begin{array}{l}\text { Use your device to scan } \\
\text { and read the article online }\end{array}$ & dtat on Omidi MR, Omidi N, Asgari H. Evaluation of Accident and Disaster Preparedness of Hospitals Affiliated to Ahvaz \\
\hline 口ifing & $\begin{array}{l}\text { Jundishapur University of Medical Sciences, Ahvaz, Iran. Health in Emergencies and Disasters Quarterly. 2019; 4(2):79-84. http:// } \\
\text { dx.doi.org/10.32598/hdq.4.2.79 }\end{array}$ \\
\hline 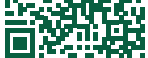 & dol http://dx.doi.org/10.32598/hdq.4.2.79 \\
\hline
\end{tabular}

\section{(i) (3)}

Article info:

Received: 25 Jun 2018

Accepted: 20 Oct 2018

Available Online: 01 Jan 2019

\section{Keywords:}

Accidents, Hospital, Disasters

\section{A B S T RACT}

Background: Hospitals, as the first and most important treatment centers for injured people, should be prepared before the crisis to provide health care services in the best possible manner, with appropriate and prompt action. The current study aimed at investigating the accident and disaster preparedness of hospitals affiliated to Jundishapur University of Medical Sciences in Ahvaz, Iran

Materials and Methods: The statistical population of the current descriptive, cross sectional study was all hospitals affiliated to Ahvaz Jundishapur University of Medical Sciences in 2017. The main tool to collect information in the study was the checklist of preparedness for disasters designed by Hojjat et al. A group of 20 faculty members of the Jundishapur University of Medical Sciences evaluated the checklist and confirmed its validity. Also, the reliability of the instrument was evaluated using a test-retest method on one of the research units based on Kappa test with a value of 0.8 in acceptable range. Data were collected and coded with SPSS software version 19 .

Results: The highest level of disaster preparedness at Jundishapur University of medical sciences in Ahvaz belonged to human inferiority with an average score of $67.66 \pm 8 ; 16$ of 100 , and the lowest belonged to the emergency areas with an average score of $3.75 \pm 0.77$ or 43 of 100. Imam Khomeini Hospital was in a better status than the other hospitals in terms of emergency, reception, discharging and transferring, traffic, and communication. In terms of education, Abuzar Hospital had the highest level of preparedness; and regarding support and management of health care practices, Salamat Hospital had the highest level for disaster preparedness.

Conclusion: The preparedness of hospitals affiliated to Jondishapour University was in moderate status and Imam Khomeini Hospital had the highest level of accident and disaster preparedness. 


\section{Introduction}

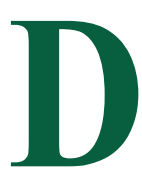

isasters are unavoidable conditions and their destructive effects can lead to the inability of the community to meet their needs and access to health care [1]. The severity of disasters is increasing worldwide and resulting in the prevalence of deaths and diseases as well as rising economic costs [2]. Iran is ranked $4^{\text {th }}$ in terms of disaster occurrence in Asia and $6^{\text {th }}$ in the world, 31 out of 40 disasters occur in Iran, and are likely to occur in the future [3].

Past experiences in Iran show that coping with disasters and their complications is a challenge and concern for authorities, and Disaster Management System (DMS) of Iran is always involved in serious problems [1]. Research shows that when a disaster occurs, the pick of medical care needs is within the first 24 hours after the disaster, and $85-95 \%$ of the survivals are rescued within first 24 hours [4]. Therefore, in times of crisis, hospitals need to increase their capacity for admission.

Medical disaster refers to human response to unexpected catastrophes aimed at reducing deaths and injuries.In the last decade, the medical response focused on hospital care such as discharge, triage, and transmission without the need for hospital treatment [5]. Certainly, health sectors play the main role in crisis management by providing preparedness plans and crisis response strategies, which can have a significant impact on reducing casualties [6]. The health sector should be prepared before the crisis to provide health care at the best possible time with adequate and prompt action [7].

By providing timely health services, health sectors can play a critical role in crisis management by reducing mortality and increasing the number of survivors, minimizing the effect of disabilities, and relieving physical and mental illnesses [7, 8]. American College of Emergency Physicians in 2003 issued a statement that all hospitals should have a place and program to provide medical care in the form of emergency preparedness, and it is essential that the program stays active and is periodically reviewed. Hospitals that regularly practice the programs are less likely to suffer in disasters [9].

Studies show that the preparedness level of hospitals in Iran is not favorable. In a study, the preparedness level of Tehran hospitals was reported "poor", and their admission capacity was less than the number of potential injuries in the time of crisis [10]. Vahedparast et al. (2013) in their study showed that the disaster prepared- ness of hospitals in Bushehr Province was very poor [11]. Daneshmandi et al. (2014) reported that in hospitals of Tehran, the preparedness of emergency, security, support, staffing, and management departments was at good level, while the department of traffic was at poor level, and units of admission, communication, training, transfer, and discharge were at average level [12].

Khuzestan Province, on the Zagros Mountains Belt, is located in the seismic regions of Iran. In addition to earthquake, this province is at high risk for other disasters and events such as dust storms. Therefore, the preparedness of the health care providers in this province is very important. Despite the fact that in the preparation of hospitals, there is a need for equipment for a disaster plan and maneuver for all hospital members, there are not standard facilities and valid methods for hospital preparation. In order to prepare for the care of many casualties, a hospital should have adequate facilities, equipment, space, as well as qualified medical and nonmedical personnel.

Measuring the disaster preparedness of hospitals makes administrators aware of the performance, weaknesses, and strengths of units in case of disasters. According to previous studies, so far no study is conducted on disaster preparedness of hospitals affiliated to Ahvaz Jundishapur University of Medical Sciences (AJUMS) as the main medical center in the Southwest of the country. Hence, the current study aimed at assessing disaster preparedness of the hospitals in Ahvaz.

\section{Materials and Methods}

The current descriptive, cross sectional study was conducted in 2016 on a population consisting of all hospitals affiliated to AJUMS including Shafa, Baghaei, Razi, Sina, Abuzar, Salamat, Golestan, Imam Khomeini, and Taleghani. All hospitals were selected by census method. Data collection tool was the checklist designed by Hojat et al. (2008) [13] with an acceptable validity and reliability. It has 210 items to measure disaster preparedness of hospitals in terms of emergency (10 items), admission (24 items), discharge and transfer (30 items), traffic (15 items), communication (16 items), security (17 items), training (17 items), support (18 items), manpower (21 items), and management (22 items).

The items are scored as $1=$ Yes or $0=$ No. Due to the lack of uniformity of items for each area, for homogeneity, the score obtained in each field was increased to 100 and for scoring, points 0 to 100 were used. It was divided into five levels: scores 0-20 indicate very poor, 
21-40 poor, 41-60 moderate, 61-80 good, and 81-100 show very good level of disaster preparedness. These cutoff points are according to approaches used by similar studies [2, 3]. After obtaining permission from AJUMS and the hospitals under study, researchers completed the checklist as an observer. In cases the observation of units was not possible, the researchers completed the checklist through interviewing with hospital managers.

To determine the validity of the questionnaire (face and content validity), the checklist was sent to 20 faculty members of AJUMS and they verified its validity. Its test-retest reliability was analyzed on one of the scales using the kappa statistic that was 0.8. Collected data were analyzed with SPSS V. 19.

\section{Results}

Table 1 presents the information of all the studied hospitals including their number of active beds, bed occupancy rate, and average length of stay. Scores of all hospitals based on the 10 scales of preparedness are presented in Table 2. As can be observed, the highest score in disaster preparedness was related to manpower scale with a Mean of $67.86 \pm 8.16$ (of 100 points), and the lowest score belonged to emergency area $(43.3 \pm 5.77)$.

Imam Khomeini Hospital was in better status compared with other hospitals in terms of emergency, admission, discharge and transfer, traffic, communication, security, and manpower. In terms of training, Abuzar Hospital was at a better level of preparedness; and with respect to support and management, Salamat Hospital was in better conditions. The mean total scores for the studied hospi- tals are shown in Table 3. It can be observed that out of the eight hospitals, six were at average level of disaster preparedness, and Imam Khomeini and Taleghani hospitals were at good level.

\section{Discussion}

The results of the current study showed that the disaster preparedness status of hospitals affiliated to AJUMS was moderate, which was consistent with the findings of Sabzghabaie et al. (2013) studying the hospitals affiliated to Shahid Beheshti University of Medical Sciences in Tehran [14], and Fazli et al. (2012) assessing Iranian Red Crescent Hospital in Mecca, the KSA [15]. In the current study, among disaster preparedness components, "emergency" got the lowest scores, and the hospitals were at moderate level with respect to this scale.

In the study by Vahedparast et al. (2013) the preparedness status for emergency response to disasters in hospitals affiliated to Bushehr University of Medical Sciences was reported good [11], while in the study by Hojat et al. (2008) on hospitals affiliated to Tehran University of Medical Sciences, the emergency preparedness was at moderate level [13].

In the current study, the mean readiness score of hospitals in terms of admission, and discharge and transfer was 50 out of 100 . In the study by Daneshmandi et al. (2014) hospitals were also in moderate level in these areas [12]. Planning and employment of special facilities such as emergency stairs, equipped entrance halls for crisis time, formation of groups and authorities to guide the

Table 1. Information of the studied hospitals

\begin{tabular}{cccc}
\hline Hospital & Number of Active Beds & Bed Occupancy Rate & Average Length of Stay \\
\hline Taleghani & 84 & 66 & 12.4 \\
Shafa & 115 & 76 & 6 \\
Baghaei & 365 & 68 & 5.5 \\
Razi & 203 & 77 & 3.4 \\
Sina & 193 & 83.4 & 5.7 \\
Abuzar & 124 & 65.4 & 4.6 \\
Salamat & 164 & 63.7 & 2.9 \\
Golestan & 468 & 65.6 & 6.2 \\
\hline Imam Khomeini & 538 & 73 & 4.2 \\
\hline
\end{tabular}


Table 2. Disaster preparedness scores of the studied hospitals based on ten scales

\begin{tabular}{|c|c|c|c|c|c|c|c|c|c|c|}
\hline 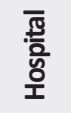 & E & A & D\&T & $T$ & C & $S$ & TR & $S$ & MP & M \\
\hline$\frac{\frac{\pi}{\pi}}{\pi}$ & 40.00 & 37.50 & 46.67 & 66.67 & 50.00 & 58.82 & 70.59 & 61.11 & 57.14 & 63.64 \\
\hline יד: & 36.67 & 45.83 & 40.00 & 73.33 & 50.00 & 70.59 & 41.18 & 44.44 & 61.90 & 59.09 \\
\hline$\stackrel{\mathscr{0}}{=}$ & 43.33 & 45.83 & 43.33 & 66.67 & 43.75 & 52.94 & 52.94 & 61.11 & 71.43 & 59.09 \\
\hline \begin{tabular}{l}
$\frac{\bar{N}}{7}$ \\
\multirow{2}{*}{}
\end{tabular} & 46.67 & 50.00 & 56.67 & 60.00 & 43.75 & 64.71 & 70.59 & 44.44 & 66.67 & 68.18 \\
\hline $\begin{array}{l}\text { 苋 } \\
\frac{E}{\mathbb{\pi}} \\
\frac{\pi}{\mathbb{N}}\end{array}$ & 40.00 & 54.17 & 46.67 & 60.00 & 56.25 & 70.59 & 47.06 & 66.67 & 71.43 & 77.27 \\
\hline 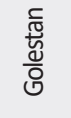 & 36.67 & 45.83 & 53.33 & 46.67 & 56.25 & 76.47 & 35.29 & 61.11 & 57.14 & 68.18 \\
\hline 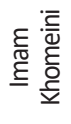 & 53.33 & 62.50 & 60.00 & 80.00 & 62.50 & 88.24 & 64.71 & 61.11 & 80.95 & 72.73 \\
\hline $\begin{array}{l}\overline{\frac{1}{\pi}} \\
\frac{\pi}{50} \\
\frac{0}{10} \\
\frac{0}{10}\end{array}$ & 50.00 & 58.33 & 53.33 & 60.00 & 56.25 & 58.82 & 64.71 & 50.00 & 76.19 & 72.73 \\
\hline 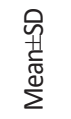 & $43.33 \pm 5.77$ & $50 \pm 7.51$ & $50 \pm 6.45$ & $64.17 \pm 9.39$ & $52.34 \pm 6.20$ & $67.65 \pm 10.60$ & $55.88 \pm 12.82$ & $56.25 \pm 8.07$ & $67.86 \pm 8.16$ & $67.61 \pm 6.20$ \\
\hline
\end{tabular}

E: Emergency; A: Admission; D\&T: Discharge and Transfer; T: Traffic; C: Communications; S: Security; TR: Training; S: Support; MP: Manpower; M: Management

patients, and conducting regular maneuvers can increase the level of preparedness in these areas.

Regarding communication preparedness during disasters, the studied hospitals reported a mean score of 52.34 out of 100. In the study by Shojaei and Maleki (2008), hospitals were at better conditions [16]. The first need for crisis planning is communication and exchanging information among organizations and hospitals. Evidence shows that by the passage of time and gaining crisis experiences, hospitals, and in particular, medical centers of large cities are thinking about equipping and developing guidelines for alternative communications in emergencies; but evidence still shows a low level of preparedness in this area, which can cause problems for emergency response to disasters due to poor communication causes, lack of coordination between the organizations, and the resulting chaos may multiply the effects of the crisis.

Table 3. The mean total scores of disaster preparedness of the studied hospitals

\begin{tabular}{ccccccccc}
\hline Hospital & Shafa & Razi & Sina & Abuzar & Salamat & Golestan & $\begin{array}{c}\text { Imam } \\
\text { Khomeni }\end{array}$ & Taleghani \\
\hline Mean \pm SD & $55.21 \pm 10.65$ & $52.30 \pm 12.42$ & $54.04 \pm 9.70$ & $57.17 \pm 9.79$ & $59.01 \pm 11.7$ & $53.70 \pm 12.41$ & $68.61 \pm 10.66$ & $60.04 \pm 8.14$ \\
$\begin{array}{c}\text { Preparedness } \\
\text { status }\end{array}$ & Moderate & Moderate & Moderate & Moderate & Moderate & Moderate & Good & Good \\
Rank & 5 & 8 & 6 & 4 & 3 & 7 & 1 & 2 \\
\hline & & & & & & $\begin{array}{c}\text { Illealth in } \\
\text { Emergencies and (D) isasters [Oluarterly }\end{array}$
\end{tabular}


In terms of support, the preparedness level of hospital was in the upper middle range. Li et al. (2008) in their study on hospitals in China reported favorable preparedness status of hospitals; $53.1 \%$ had evaluated stockpiles of drugs; $61.5 \%$ had evaluated their supply systems; and $55.5 \%$ had developed surveillance systems [17]. If hospitals receive more support in disaster, it can result in lower losses caused by disasters. It seems that the allocation of costs and the necessary facilities to equip hospitals can increase the efficiency in dealing with disasters. The results of the current study reported the disaster preparedness of hospitals in terms of security and traffic as "good".

Treat et al. (2001) showed that $77 \%$ of hospitals had a facility security plan in place; however, they had equipment defects [18]. In the study by Maleki et al. (2007) study subjects were at moderate level in terms of having a security plan [19]. Familiarization of security personnel and improvement of security facilities is very important in disaster management, and the readiness of hospitals in this area should be monitored continuously. The highest level of disasters preparedness in AJUMS hospitals was related to manpower area, which was in good condition. Results of Zaboli showed that hospitals of Tehran University of Medical Sciences were at good status in terms of human resources and staffing [10]. With regard to the appropriate capacity in terms of manpower in the studied hospitals, it is possible to improve their preparedness by describing the duties of human resources manager and staff, and formulating the instructions of staff's psychological counseling sessions.

All hospitals should have a strategic, comprehensive, and standardized plan to deal with disasters, but unfortunately, most of these plans are often neglected due to paying attention to daily needs to provide proper services. Since hospital situations are completely changed in the event of accidents and disasters, the adaptation of these situations to new conditions should be done on the basis of projected plans, and everyone should be prepared according to the specified responsibilities.

\section{Conclusion}

It was concluded that hospitals affiliated to AJUMS were moderately prepared to deal with a disaster. Among the studied hospitals, Imam Khomeini Hospital had higher level of preparedness. Results of the current study revealed that the hospitals affiliated to AJUMS had the capacity to increase their preparedness at the time of disasters, and their managers need to make tactical and strategic decisions (short-term and long-term) in order to bring this preparedness to a favorable condition.
According to the better disaster preparedness of Imam Khomeini Hospital compared with the other studied hospitals, it is suggested that successful experiences, plans, and activities of this hospital should be shared with the other hospitals with low level of preparedness to improve their conditions and readiness.

\section{Ethical Considerations}

\section{Compliance with ethical guidelines}

All participants were allowed to withdraw from the study at any time. This study was conducted according to the ethical guidelines No. 7, 8, 17 provided by the Ethics Committee of Medical Sciences University.

\section{Funding}

This research did not receive any specific grant from funding agencies in the public, commercial, or not-forprofit sectors.

\section{Authors contributions}

Writing text and doing calculations: Mohammad Reza Omidi; Interviewing and distributing questionnaires: Nabi Omidi; and Data collection and analysis: Heshmatolah Asgari.

\section{Conflict of interest}

The authors declared no conflict of interest.

\section{References}

[1] Ardalan A, Rajaei MH, Masoumi G, Azin A, Zonoobi V, Sarvar M. 2012-2025 roadmap of I.R. Iran's disaster health management. PLOS Currents. 2012; 4:e4f93005fbcb34. [DOI 10.1371/4f93005fbcb34].

[2] Bagaria J, Heggie C, Abrahams J, Murray V. Evacuation and sheltering of hospitals in emergencies: A review of international experience. Prehospital and Disaster Medicine. 2009; 24(5):461-7. [DOI:10.1017/S1049023X00007329]

[3] Hojat M. [Disaster management in hospital (Persian)]. Tehran: Boshra Publication; 2010.

[4] Dargahi A, Farrokhi M, Poursadeghiyan M, Ahagh MMH, Karami A. Evaluation of functional preparedness and non structural safety of different health units of Kermanshah university of medical sciences in coping with natural disasters. Health in Emergencies and Disasters Quarterly. 2017 2(4):201-6. [DOI:10.29252/nrip.hdq.2.4.201] 
[5] Radovic V, Vitale K, Tchounwou PB. Health facilities safety in natural disasters: Experiences and challenges from South East Europe. International Journal of Environmental Research and Public Health. 2012; 9(5):1677-86. [DOI:10.3390/ ijerph9051677] [PMID] [PMCID]

[6] Pourtaghi GhH, Hekmat M, Rafati Shaldehi H, Salem M. [Hospital accidents prevalence rate and its affective agents in a military hospital staffs (Persian)]. Iranian Journal of Military Medicine. 2011; 13(1):53-57.

[7] Khademipour G, Sheikh Bardsiri H, Yar Mohammadian MH, Nekuyi Moghadam M. [Hospitals capability in response to disasters considering surge capacity approach (Persian)]. Health in Emergencies and Disasters. 2016; 1(2):111-8.

[8] Seyedin H, Abasi Dolat Abadi Z, Sorani M, Naghdi S, Rajabfard Mazraeno F. [Vulnerability assessment of general hospitals of Tehran University of Medical Sciences (Persian)] Journal of Health Policy and Management. 2014; 3(2):65-71.

[9] Hoseinishokoh SM, Arab M, Rahimi A, Rashidiyan A, Sadremomtaz N. [Preparation rate the hospitals of Iran University of Medical Sciences and Health Services to the earthquake (Persian)]. Journal of Public Health faculty and Research Health Institute. 2008; 6(3,4):61-77.

[10] Zaboli R, Tofighi Sh, Amerion A, Moghaddasi H. [Survey of Tehran City hospitals disaster preparedness for disaster (Persian)]. Journal of Military Medicine. 2006; 8(2):103-11.

[11] Vahedparast H, Ravanipour M, Hajinezhad F, Kamali F, Gharibi T, Bagherzadeh R. [Assessing hospital disaster preparedness of bushehr province (Persian)]. Iranian South Medical Journal. 2013; 16(1):69-76.

[12] Daneshmandi M, Nezamzadeh M, Zareiyan A. Assessment the preparedness of selected hospital to deal with disasters in Tehran. Military Caring Sciences Journal. 2014; 1(1):2835. [DOI:10.18869/acadpub.mcs.1.1.28]

[13] Hojat M, Siratinir M, Khaghanizadeh M, Karimizarchi M. [A survey of hospital disaster management in Medical Science Universities (Persian)]. Daneshvar Medicine. 2008; 15(74):1-10.

[14] Sabzghabaie A, Kondori A, Shojaee M, Kamrani Rad A, Amini A, Hatamabadi HR. [Hospital safety in hospitals affiliated with Shahid Beheshti University of Medical Sciences in 2011-13 (Persian)]. Pajoohande. 2013; 18(2):83-7.

[15] Fazli H, Hedayat M, Mortazavi M, Alibeigi M. [Assessment of disaster management system vulnerability during critical conditions in Iranian Red Crescent Hospital in Hajj in Mecca (Persian)]. Journal of Rescue \& Relief. 2012; 3(4):1-5.

[16] Shojaei P, Maleki MR. [A key element of disaster preparedness in hospitals (Persian)]. Teb va Tazkiye. 2008; 17(4):77-86.

[17] Li X, Huang J, Zhang H. An analysis of hospital preparedness capacity for public health emergency in four regions of China: Beijing, Shandong, Guangxi, and Hainan. BMC Public Health. 2008; 8:319. [DOI:10.1186/1471-2458-8-319] [PMID] [PMCID]

[18] Treat KN, Williams JM, Furbee PM, Manley WG, Russell FK, Stamper CD Jr. Hospital preparedness for weapons of mass destruction incidents: An initial assessment. Annals of Emergency Medicine. 2001; 38(5):562-5. [DOI:10.1067/ mem.2001.118009] [PMID]
[19] Maleki M, Nasiripour A, Aghababa S. [Knowledge management of emergency department in Rasul Akram Hospital based on Baldrige excellence model in 2007 (Persian)]. Health Information Management. 2007; 4(2):167-74. 